IBIMA Publishing

Journal of e-learning and Higher Education

http://www.ibimapublishing.com/journals/JELHE/jelhe.html

Vol. 2015 (2015), Article ID 426195, 14 Pages

DOI: $10.5171 / 2015.426195$

Research Article

\title{
Multi-Agent based Model for e-Learning in Entrepreneurship
}

\author{
Radu Ioan Mogos ${ }^{1}$ and Constanta-Nicoleta Bodea ${ }^{2}$ \\ ${ }^{1}$ Bucharest University of Economic Studies, Romania \\ ${ }^{2}$ Bucharest University of Economic Studies, Centre of Industry and Services Economics of the \\ Romanian Academy, Romania
}

Correspondence should be addressed to: Radu loan MOGOS; mogos.radu@gmail.com

Received date: 8 September 2014; Accepted date: 17 January 2015; Published date: 26 June 2015

Academic Editor: Rahul Kulkarni

Copyright (C) 2015. Radu Ioan Mogos and Constanta-Nicoleta Bodea. Distributed under Creative Commons CC-BY 4.0

\begin{abstract}
In the past decade, a lot of educational programs for entrepreneurship have shown an increased interest in competences development, using innovative learning approaches. Some of them are based on educational simulations. The increasing availability of the simulation platforms and access to them also contribute to the improvement of simulation in entrepreneurship education. The aim of this paper is to present an architectural model for e-learning in entrepreneurship using agent-paradigm based simulations. The architecture of the e-learning platform was defined using ARCHIMATE model and language. The business, information and technology levels were designed. The defined architecture model includes the most important structural elements and also the main dynamic elements of the e-learning platform, offering information about the development of the agent-based platform. Taking into account the proposed model, the authors identified further directions for development.
\end{abstract}

Keywords: entrepreneurial, entrepreneurial education, e-learning platform, architectural model, multi-agents system.

\section{Introduction}

Entrepreneurship, according to X-Bdict (2014) represents "the capacity and willingness to develop, organize and manage a business venture along with any of its risks in order to make a profit". It may also have a big impact on the economic development. An important part of it is represented by the innovation, which involves the development of new sources of supply, new products, new processes, but also the exploitation of new markets and the development of new ways to organize business (Braunerhjelm (2010), Szirmai, Naudé, and Goedhuys, (2011), Vicens and Grullón (2011), OECD (2011)).

As a consequence, Baumol (1968) suggests that entrepreneurship absence is connected to difficulties of balance-of-payment and industry declining. Taking this into

Cite this Article as: Radu Ioan Mogos and Constanta-Nicoleta Bodea (2015), "Multi-Agent based Model for e-Learning in Entrepreneurship", Journal of e-learning and Higher Education, Vol. 2015 (2015), Article ID 426195,

DOI: $10.5171 / 2015.426195$ 
consideration, entrepreneurship is seen more and more as a possible solution to the upcoming crises by policy makers and scholars (Oosterbeek, van Praag, and Ijsselstein (2010), Paolillo (2014)).

Several initiatives at the international level were taken. One of this belongs to the European Commission (EC) which has started the "Entrepreneurship 2020 Action Plan and the Rethinking Education Communication". Through it, the EC in EU (2013) has highlighted the need to embed entrepreneurial education (EE) in all sectors of education, including non-formal learning. In this context, the entrepreneurial education is seen as a way of developing entrepreneurial attitudes, skills and knowledge which, in short, should enable a student to 'turn ideas into action'. In the same source is mentioned that entrepreneurial competences require active methods of engaging students to release their creativity and innovation, also entrepreneurial competency and skills can be acquired or built only through real life learning experiences. It concludes that the EE should be promoted beyond teacher education institutions to businesses and the wider community, encouraging young people to take part in educational programs that offer practical entrepreneurial experience.

In recent years, there has been an increasing interest in EE. However, there are still a lot of difficulties that must be overtaken. One of these difficulties lies in identifying the competencies that are offered by such educational programs. There is still a major issue regarding the competences repository and the way they are taught. In some cases, there might be some common elements between competencies. However, the specific entrepreneurial competencies should be considered by every educational program where entrepreneurship is taught.

Ronstad (1985) indicates 14 skills that must be developed and improved during the EE. Some of them are creativity, ambiguity tolerance, opportunity identification and venture evaluation, career assessment, deal making, networking, and ethical assessment. In Garavan and O'Cinneide (1994), it is mentioned that the following elements are more often encountered: reality - testing skills, creativity, ambiguity tolerance and stress - coping mechanisms.

According to Lackeus (2013), a comprehensive framework for competencies is composed by Knowledge (Mental models, Declarative knowledge, Self-insight), Skills (Marketing skills, Opportunity skills, Resource skills, Interpersonal skills, Learning skills, Strategic skills), Attitudes (Entrepreneurial passion, Self-efficacy, Entrepreneurial identity, Proactiveness, Uncertainty / ambiguity tolerance, Innovativeness, Perseverance).

Some important competencies are often related to particularities that characterize an entrepreneur, competencies like personal attitudes, knowledge and behavior. In van der Kuip and Verheul (2003) it is recommended that EE should be taught in an active and experiential way, stimulating the entrepreneur students to act entrepreneurial and think in a creative way.

\section{Entrepreneurship education and training methods; the role of agent-based simulations.}

One of the most significant current discussions in EE is the way in which the trainers and teachers may develop behavioral competencies and personal attitudes, elements that are very important for a good entrepreneur (Bodea, Mogos, and Dascălu, (2012)). In recent years, there has been an increasing interest in modern ways of doing EE. This consists in the fact that students must experience more the concept and the specific activities of the entrepreneurship.

In the paper by Weimer (2012), five characteristics of learned-centered teaching method (LCT) are presented, namely: engages students in the hard, messy work of learning, includes explicit skill instruction, encourages students to reflect on what they are learning and how they are learning it, motivates students by giving them some 
control over learning processes, encourages collaboration.

Several methods and tools for teaching entrepreneurship were successfully used; their results showing that they may be taken into consideration for use at a large scale (ECEE (2013)). In a research study by Arasti, Falavarjani and Imanipour (2012) a study of teaching methods in EE for Graduate Students is conducted with relevant results.

A method that might be used and has also very good results in acquiring entrepreneurship competencies is the simulation method. It allows students to test the problem solving solutions, to experience the consequences of their actions and to adjust them.

Simulations can be used to provide an adequate learning environment for students. The use of simulated activities in education, named also educational simulation (ES), is widely becoming recognized as an important tool that is used in this kind of program. ES is becoming more and more the preferred learning method for the students.

In Schindehutte (2006), some of the most notorious simulations packages, with impact over the EE are mentioned.

\section{- Entrepreneur}

(http://home.att.net/ simulations/ent re2.htm).

- GoVenture (www.goventure.net).

- Threshold Entrepreneur (www.prenhall.com/threshold).

- The Business Disc (http://online.sfsu.edu/ cmgaglio/BizD iscSimulation.PDF)

- Venture.SIM (http://simventure.co.uk/index.php)

- VCommerce (http://misweb.bus.msu.edu/acc890/re sources/vc-EntreGuide.pdf).

Agent-based simulation (ABS) is a class of computational models for simulating actions and interactions of autonomous agents with a view to assessing their effects on the system as a whole (X-ABM (2014)). According to the same source, one of the earliest agent-based models in concept was Thomas Schelling's segregation model, which was discussed in his paper Schelling (1971). In the research study by Borshchev and Filippov (2004) the authors organize the subjects of research interested by computer simulation according to their level of abstraction, precision of details, level of analysis and purpose of activity. They identify four types of possible simulations to be implemented throughout their model. These types are: Dynamic Systems (DS) (being described by mathematical models of dynamic systems), Discrete Events (DE) (which are a flowchart of the relationships among the events of a process), System Dynamics (SD) (at the macro level), descendant of Dynamic System. In the same source, it is mentioned that Agent-based Models (ABM), as a simulation method, are able to fit both social and natural systems.

In Pablo-Martí et al (2013) an agent-based model that includes all the main related variables (knowledge, innovation, entrepreneur and firm) is presented. It uses real data from several databases and makes possible to forecast the entrepreneurship and business activity at a local or country level. It provides solutions to the questions unanswered by traditional models.

Sunny Yang and Leeds (2012) propose an agent-based modeling (ABM) as an alternative approach to advance research in entrepreneurship. The proposed ABM allows entrepreneurship researchers to find better solutions to generate entrepreneurial outcomes by understanding alternative histories and examining plausible future.

\section{Developing an e-Learning Platform in Entrepreneurship for educational simulations using business scenarios}

The e-learning platform objective is to develop the entrepreneurial competencies of the students required for the identification of business opportunities and taking decisions about the product/service to be produced, the start-up strategy and the marketing and selling strategy. 
There many ways to identify business opportunities, reading business materials, talking to people, and asking questions such as: What are the limitations of the existing products and services? What would you like that is not available? What are innovative ways to use or to provide existing products? An entrepreneur can decide to produce an existing product/service for an existing market, a new product/service for a new market, a new product/service for an existing market or an existing product/service for a new market. In order to decide what product or service to provide, the entrepreneur should consider many factors, including the idea's market potential, the competition, financial resources, risks and its own skills and interests. Then, the entrepreneur should decide the start-up strategy, meaning innovation, differentiation, or niche specification. Another important decision is about the marketing and selling strategy to be adopted.

The e-learning platform has different components, which can be used together or separately, according to the educational settings. The main components are the following:

- $\quad$ A meta-search engine, which screens the web in order to find information about business opportunities (statistic data about business activities, main competitors, success story and other case studies etc). The selected web documents will be classified and summarized in order to be more accessible to students. This component will offer valuable examples to the students of how the business opportunities could be identified, how the search can be managed and the relevant retrieved documents can be organized and analyzed.

- An agent-based simulation (ABS) component, which develops business scenarios, based on decision alternatives about the product/service, start-up and marketing strategies. The students introduce the main parameters required for these scenarios. In order to be domain-independent, the parameters are generic, such as: business type, aspects and criteria. Using these parameters, the ABS component develops different scenarios and will simulate a negotiation process in order to identify the best business scenario. The students have access to the results of every negotiation phase, in order to learn how different business scenarios can be assessed.

- A risk analysis component, assists students to perform quantitative risk analysis for business scenarios. This component has a powerful graphical interface, that provide support in understanding the significance of the results generated by different probabilistic methods applied in risk analysis, such as Monte Carlo.

The following paragraphs present the architectural model of the ABS component.

A. The need for defining an architectural model. The architectural models assist the IT solution decisions, by promoting interoperability between platforms, expanding the flexibility and scalability, increasing portability, and productivity, improving modularity and component reusing, and reducing short and long term risks. Any architectural model is developed using underlying principles, services, standards, concepts, components, display modes and configurations.

The main advantage of using the architectural model (AM) consist in defining the problem using a common vocabulary that allows each actor involved in the problem solving to communicate and cooperate with others. The AM allows the design of IT solutions' architecture based on business characteristics. It brings attention to some processes, which require artifacts in order to improve their performance. It highlights the links between business requirements, information architecture and technology architecture. The AM significantly reduces the cost of developing complex information systems and provides accurate predictability for the delivery time.

The architectural model for e-Learning in Entrepreneurship was defined using an 
ARCHIMATE model, v.1, aligned to IEEE 1471 standard. This model type has the ability to easily gather the views of the participants involved in the development and implementation of a business. Among the elements that were considered in the modeling process, there are actors, roles, business services, functions and applications and the infrastructure. The architecture is structured on the following three levels: the business level (it includes processes, functions, services and events, providing products and / or services to external clients), the information or applications level (it describes the software that supports business components by means of the application services) and the technological level (it includes hardware and communications infrastructure and it describes the architecture required for applications, providing infrastructure services to run different applications).

The ARCHIMATE model has a modeling language that is recognized as an international standard in the design and description of the enterprise architecture and that is used to describe the business processes, organizational structure, information flows and data, IT systems and technology infrastructure. This modeling language is different from other modeling languages, like UML (Unified Modeling Language) or BPMN (Business Process Modeling Notation) having a three levels of approach and a reduced complexity.

B. The business architecture. Business Architecture (BA) describes the strategic elements of an organization, the organizational, functional and informational attributes, principles, processes and business functions. BA is a valuable tool in analyzing the current state of business, in setting the required changes and in selecting appropriate tools and techniques for optimal decisions. Business architecture of e-learning platform in entrepreneurship includes actors, roles, processes, functions, events, services and products (figure 1). BA describes how a student can use the e-Learning to acquire skills for developing and evaluation of a business scenario and also for the optimization of a scenario already defined. As a solution to simulate the specific activities, a multi-agent system is chosen.



Figure. 1 The business architecture

Radu Ioan Mogos and Constanta-Nicoleta Bodea (2015), Journal of e-learning and Higher Education, DOI: $10.5171 / 2015.426195$ 
Actors. There are two actors namely: "eLearning Platform" (the platform) and "Entrepreneur" (the student), each fulfilling one or more roles. Actor "E-Learning Platform" is the main component that supports learning and its related functions and services. "Entrepreneur" is the person who wants to learn, using the platform to realize a business scenario in a particular area;

Roles. There is one role owned by the platform and named e-Learning Assistant (P), and there are two roles for the student. The role e-Learning Assistant is intended to supervise the business scenario development made by the student in a particular field, providing useful business information, characteristics/aspects and evaluation criteria as well as benchmarks for all of them. The platform also offers information about what features can be improved in the proposed scenarios. The roles for the student are Pattern - Scenario Designer (PSD) and Scenario Designer (SD). The PSD role builds a business scenario in a certain area, using information received by specific searching services or provided directly by the student himself. Students enrich their knowledge about what information is needed for developing a business scenario in a specific domain of business (characteristics, values, correlations). Several Help sessions are available. The scenario developed by the student is validated by the platform and is further considered as a template (pattern) for that business domain. This template can be used by other students as a reference or can be used in data mining, if several scenario templates were developed for the same business domain. The $S D$ role simulates several business scenarios that will be compared with the template. Following the comparison, each proposed scenario will get a score and the student can see what aspects / criteria should be improved in order to obtain better scenario more similar to the template, in terms of criteria values. In the simulation sessions, each role is represented by a software agent, identified as A-P, A-PSD and A-SD.
Events. There is the event named Claim Best Scenario, which is the action that triggers the whole process of achieving optimum scenario.

Business processes. There is the Obtaining Best Scenario process that is triggered by the event Claim Best Scenario. The result of this process is the object Best Scenario. The process requires a number of specific functions of e-Learning platform, describing the learning activities. These functions are implemented using specific services. There are the following functions:

- Registration On Platform. It is a login function, creating a user profile based on the information provided by the student. The Registration service is called to perform this function.

- Choose Business Type (With Help Session 1). This function allows the student to select the area and the type of the business. The Search Data service is the call for searching business information in various sources.

- Fill Parameters By Entrepreneur. The student defines the scenario using Fulfill Service Parameters; it receives guidance from the platform through Business Data Examples service;

- Model Validation. The defined scenario is validated, comparing it with a script template, specific for that business type and domain. Data Comparison service is used. If the differences are in an acceptable range, the proposed scenario is considered valid, if not, the proposed scenario is rejected.

- Choose Aspects And Criteria (With Help Session 2). The function is used in developing business scenarios, using Fulfill service. The student sets the values for aspects / criteria using the platform's suggestions using the service Aspects and Criteria Examples.

- Propose Scenario (With Help Session 3). The function creates a business scenario based on the values provided by the student for the aspects/criteria. Create Scenario service is used.

- Learning To Choose The Best Scenario - The function provides guidance to the student 
how the business scenario can be improved. The services called by this function perform different steps in choosing the best scenario. The service Create AHP Tree builds an AHP (Analytic Hierarchy Process) tree and identifies the weight of each criterion. The service Scenario Ranking calculates the scenario score. The service Improve scenario updates the scenario and the service Best scenario announcement communicates which the best scenario is in relation to the scenario template.

In the following diagrams (Fig. 2 and 3) the main phases for the process were depicted regarding a business scenario creation taking into account the suggestions given by the eLearning platform.

a) The way in which an entrepreneur (using the Pattern - Scenario Designer - PSD role) may obtain a pattern scenario using data and information offered by the eLearning platform (e-Learning Assistant) is shown in fig. 2. In order to obtain this type of business scenario, several actions must be done, as follows: the entrepreneur must register to the platform, to choose a business type and its relevant aspects and criteria, to create a scenario based on data and information offered by the platform, to create a valid scenario approved by the platform. The scenario validation may be done using other pattern scenarios values. The final version of the scenario is stored in a database.

b) The way in which an entrepreneur may improve a proposed scenario or choose from several is shown in fig. 3. In order to offer the best scenario, the eLearning platform compares it with a pattern scenario for a specific business type. For choosing the best business scenario, several actions must be done, as follows: the entrepreneur (in the role of Scenario Designer - SD) may create a business scenario being helped by the platform (the help regards the business type, data, information, aspects and criteria specific for the chosen business type, values for criteria), the scenario evaluation made by the eLearning Platform (eLearning Assistant - eLA), suggestions made by eLA, the final approval regarding the scenario. The scenario optimization process may be done in several rounds. After that, the scenario may be tested using an economic environment simulation software. 


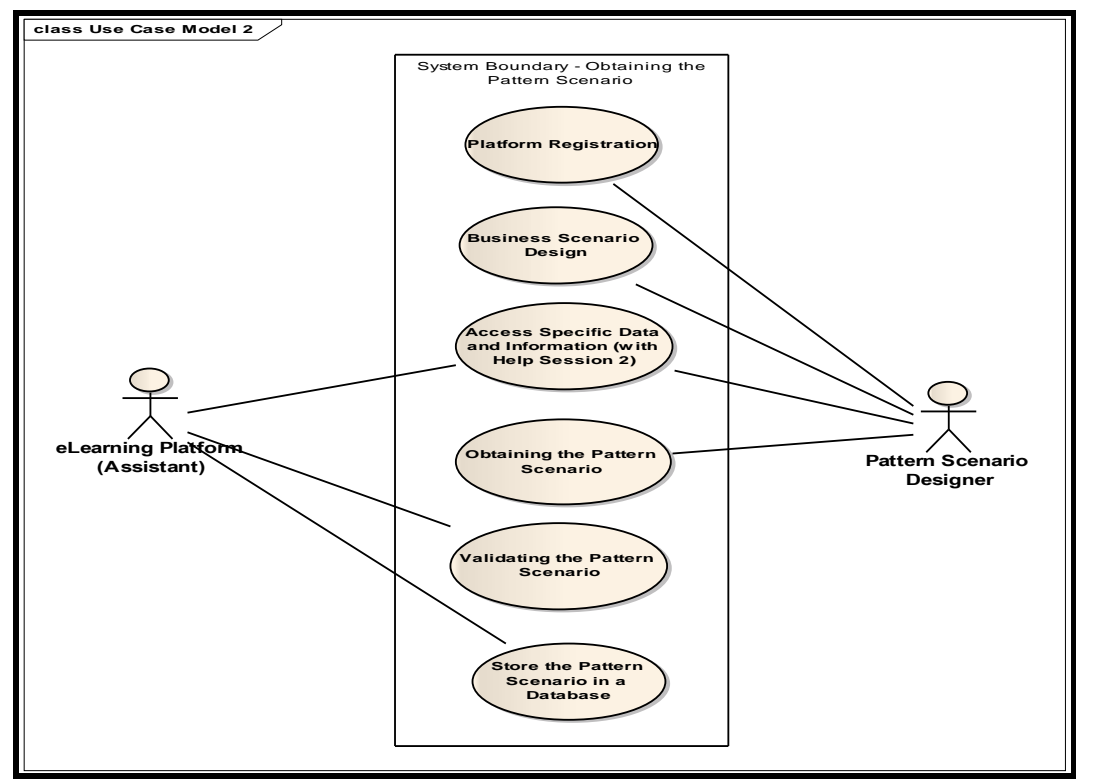

Figure. 2 eLearning Platform and Pattern Scenario Designer

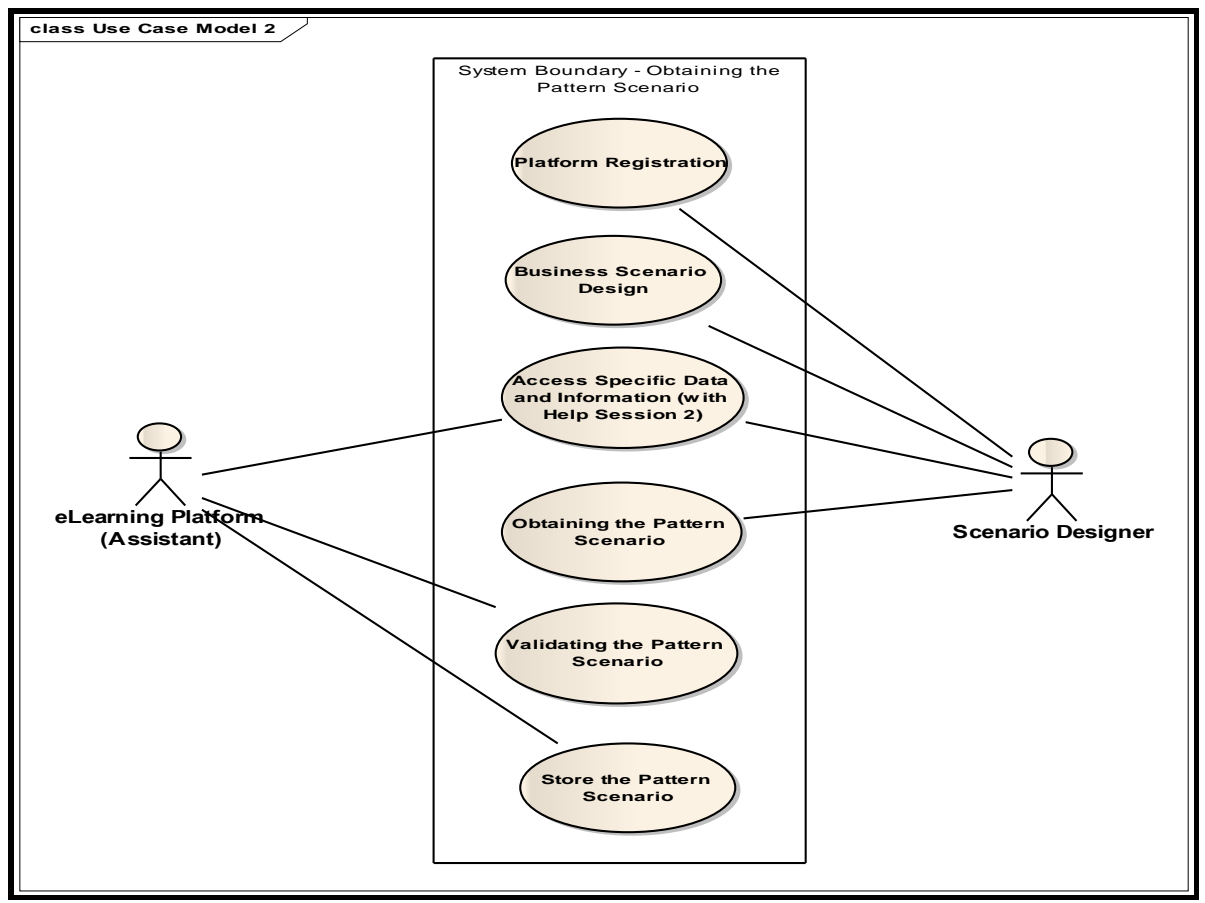

Figure. 3 eLearning Platform and Scenario Designer

c) An overview of the whole eLearning process is represented in Fig. 4, where the interactions between roles E-Learning Assistant, Pattern Scenario Design and Scenario Design are described. The last two roles 
(Pattern Scenario Design and Scenario Design) are played by the entrepreneur student. Each role is accomplished by a software agent. From the eLearning Assistant point of view, it must take care of several tasks like: to rank the proposed scenario received from entrepreneur, to compute the AHP tree, to offer examples for aspects, criteria and data, to help the entrepreneur to select the initial aspects and criteria for the proposed scenario, to validate the scenario and to advise him which aspects or criteria may be modified in order to obtain an improved scenario.
From the Pattern Scenario Design point of view, it must take care of several tasks, as follows: to claim pattern scenario creation, to fulfill the aspects and criteria options, to create a pattern scenario.

From the Scenario Design point of view, it must take care of several tasks like: to claim a creation of a business scenario, to make an initial proposal for a scenario, to modify the submitted scenario according to the suggestions offered by the PSD, to obtain a business scenario that is very possible to work in the real world.

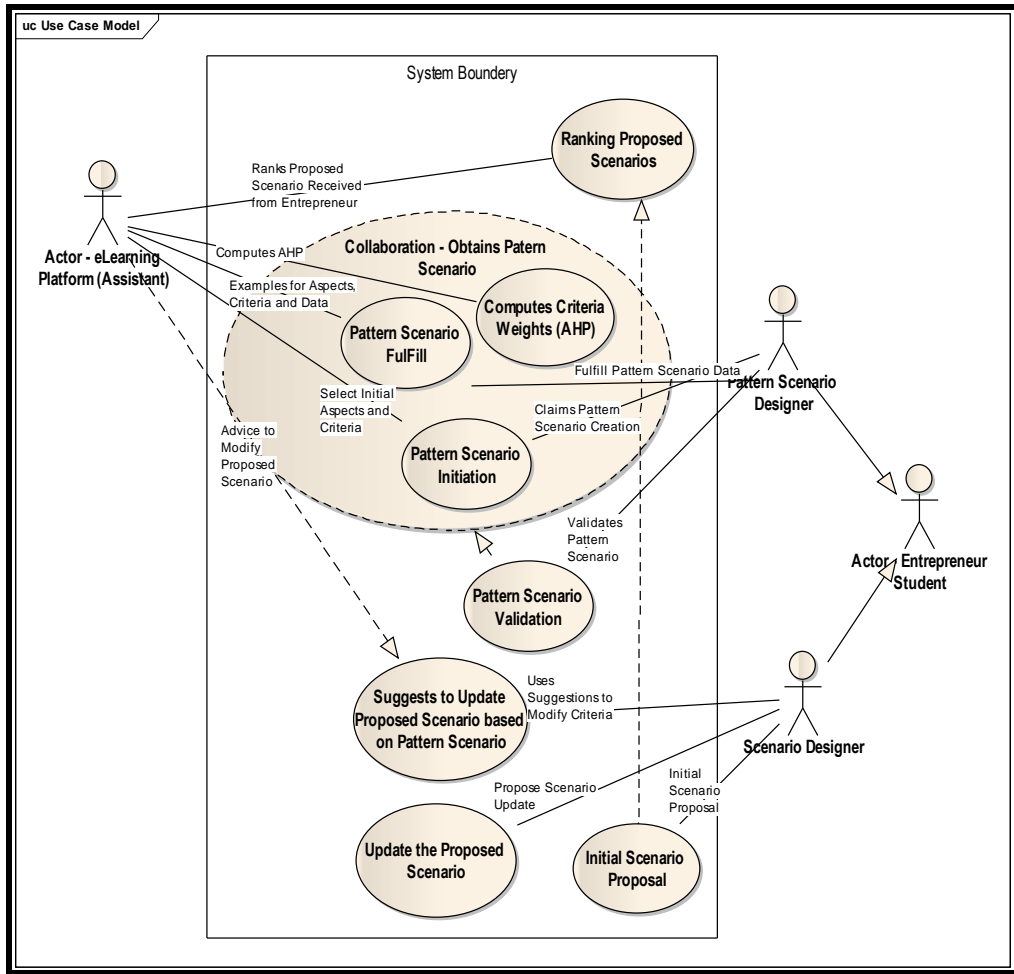

Figure. 4 The use case of an Entrepreneur Student creating a business scenario

C. The information and technology architecture. Information architecture describes data and applications that are necessary to support the defined business architecture. Several components of the information architecture are directly related to business architecture components. Information architecture aims to describe the data architecture as well as 
the applications architecture in an integrative manner. In the e-Learning platform in entrepreneurship, the information architecture contains the main function "Obtaining Best Scenario", which provides the necessary support in terms of information to obtain the best scenario (figure 5). This function uses the service "Select The Best Scenario".
The following functions are used: Data Search, Data Examples, Pattern build scenario (With AHP Tree), Create scenario (With Scenario Ranking), and Choose best scenario. The information architecture includes also Interface, which is the interface from which student can access the platform.

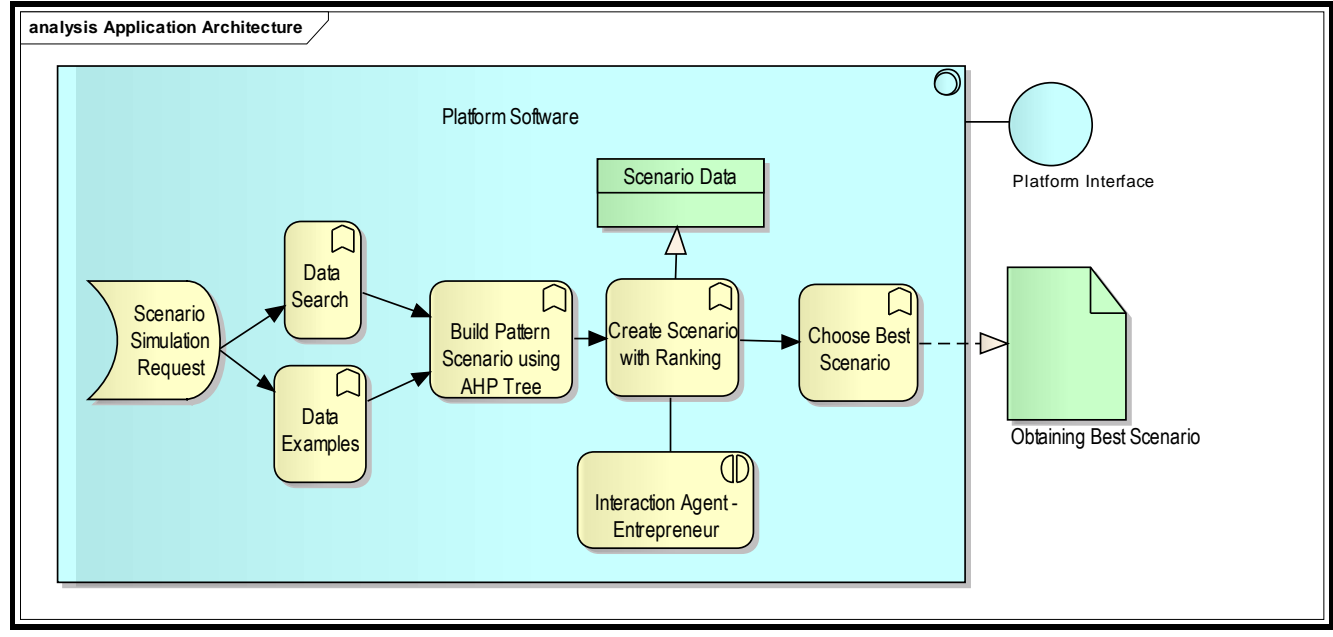

Figure. 5 The information architecture

The technology architecture describes the physical solution for the e-Learning platform in entrepreneurship (figure 6).

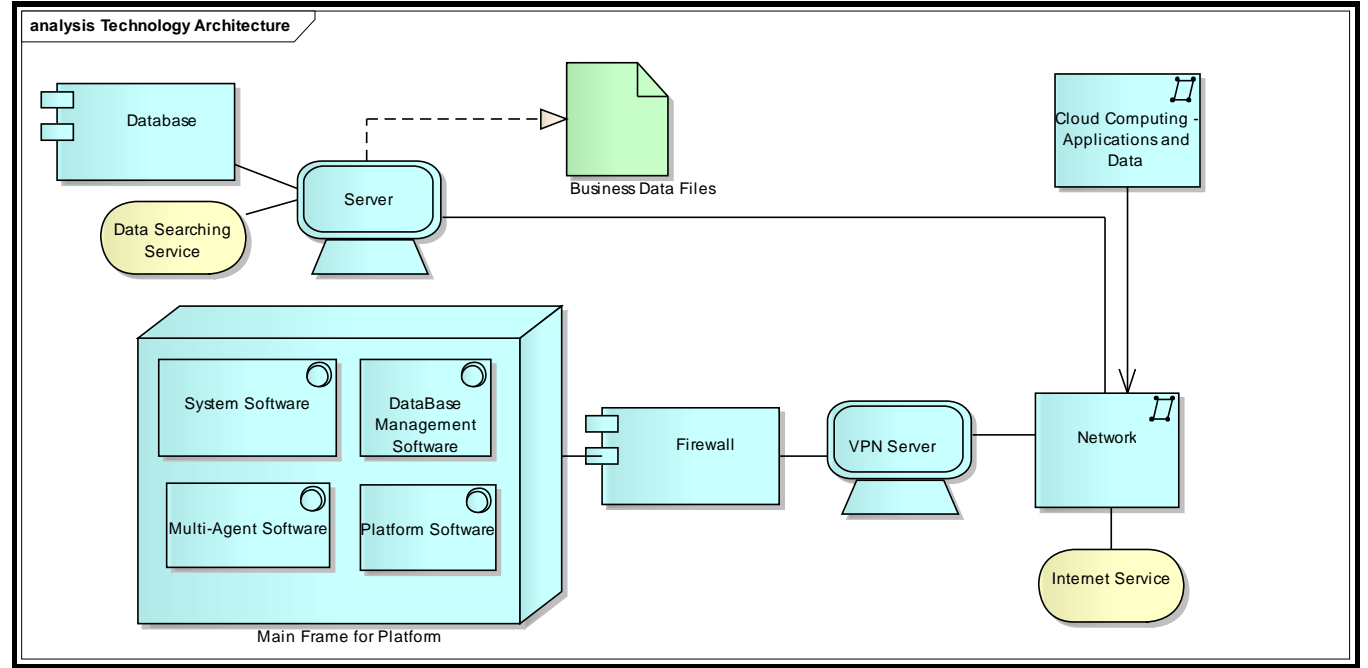

Figure. 6 The technology architecture 
The components of the technology architecture are the following:

- Software components: System Software, DB Management System, Multi-Agent Support Software and Platform Software - $\quad$ Network and server components

D. The sequence diagram. The sequence diagram for the e-learning platform is presented in figure 7. As we can see, the diagram describes the sequence of the messages sent by agents for different learning paths. Let us suppose that A-PSD (1st) / A-SD (2-nd) want to create their own template by selecting the type of business and the domain from the database. A-P (3-rd) retrieves the requested information from the database and sends it to A-PSD / A-SD agent. After the A-PSD agent builds a valid business scenario, the A-P agent calculates the criteria weights. A-SD fills the criteria values and sends the scenario to A-P. The A-P agent calculates the score of each scenario and sends a message to A-SD indicating which criterion can be improved. After several successive rounds, the best scenario can be identified.

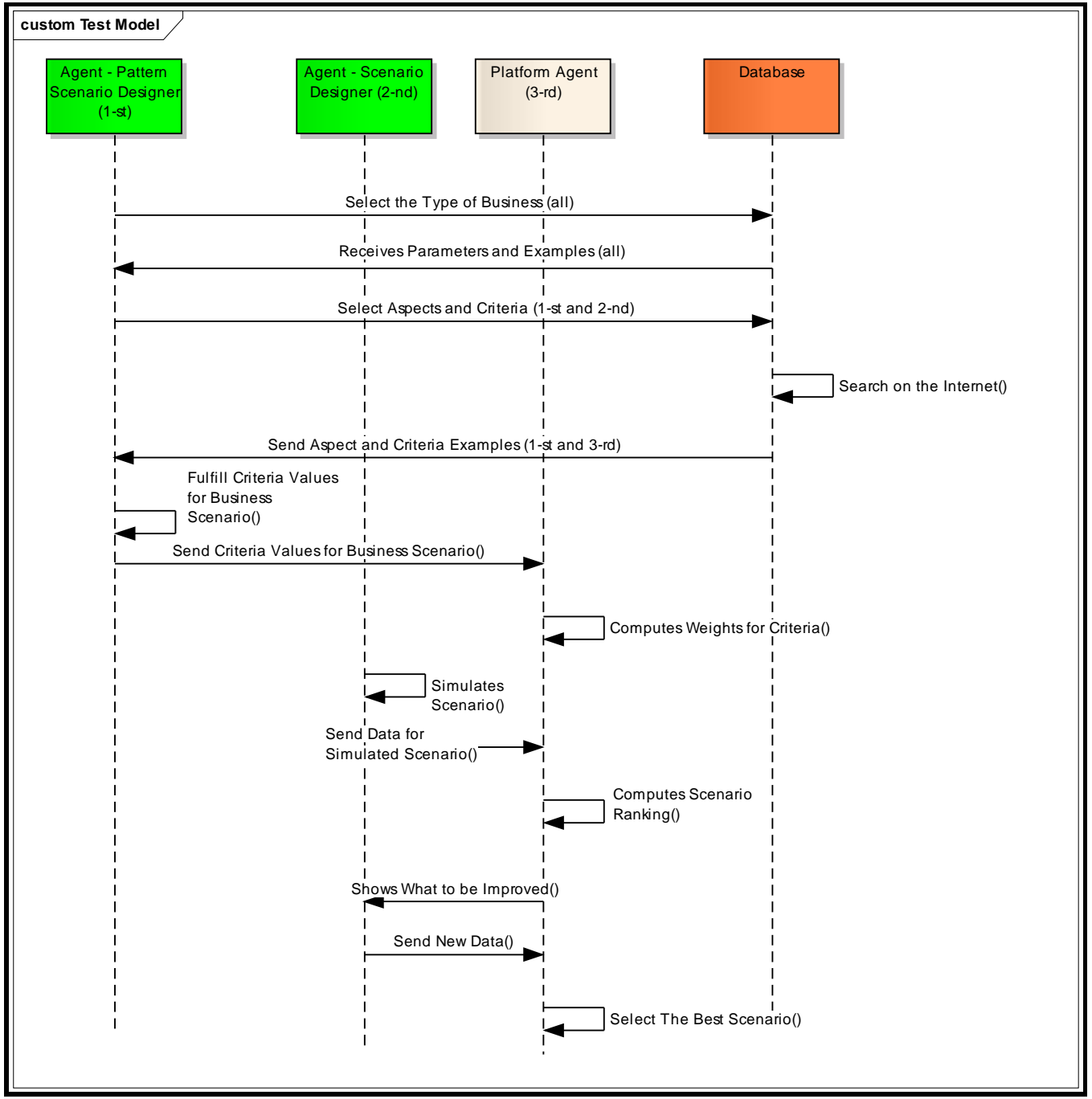

Figure.7 The sequence diagram

Radu Ioan Mogos and Constanta-Nicoleta Bodea (2015), Journal of e-learning and Higher Education, DOI: $10.5171 / 2015.426195$ 


\section{Implementation of the architectural model}

This section presents a possible approach for a partial implementation regarding the creation process of a pattern business scenario using software agents. As the development environment for the agents it was used Jade, because it is a dedicated platform that offers several facilities for multi-agent systems development. The aspects and criteria are stored into a database. From this database, according to the business type, they are submitted by an

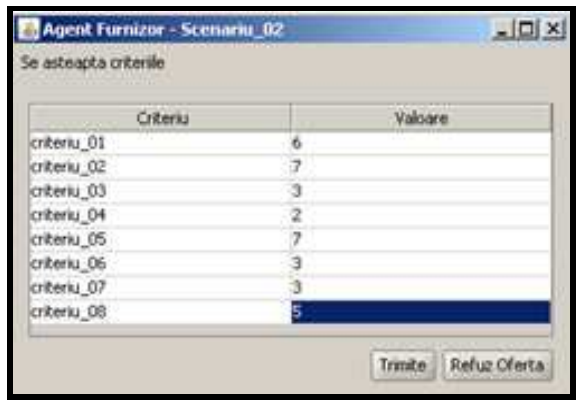

Fig. 8 Entrepreneur agent interface

The computed ranks for the three business scenarios based on 8 criteria is represented initiator agent to the platform agent and to the entrepreneur agent. In our example is simulated a situation where an entrepreneur send 3 business scenarios and the platform analyses them is simulated. Based on the values fulfilled by the entrepreneur, the platform computes a ranking table with the scenarios. During a communication round, some suggestions from the platform may be sent to the entrepreneur. In this way, he will learn, based on his business type, what is more important to modify and which are the connections between the chosen criteria.

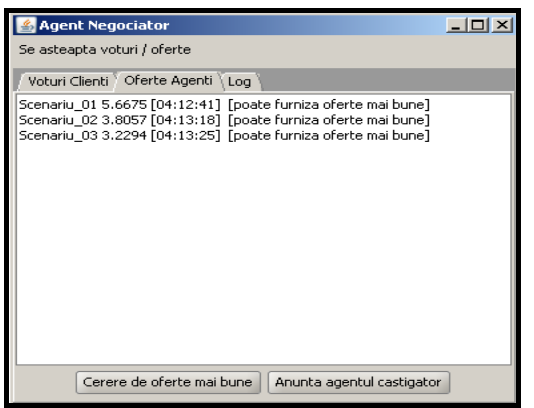

Fig. 9 Ranking table for submitted scenarios

in Tabel 1. The criteria data values for the second scenario were: $(6,7,3,2,7,3,3,5)$.

Table 1. Criteria and weight

\begin{tabular}{|l|l|}
\hline Criteria & Weight \\
\hline Scenario_01 & 5.6675 \\
\hline Scenario_02 & 3.8057 \\
\hline Scenario_03 & 3.2294 \\
\hline
\end{tabular}

\section{Conclusion and future work}

The paper proposes an architectural model for e-Learning in entrepreneurship using agent based simulation. The originality of the model is that each entity participating in the training process is represented by a software agent and the communication is done in an interactive way. In the system, the agents representing the entrepreneur student can communicate with the central agent platform for obtaining an advice in order to build a good business scenario.

Using the e-learning platform, the students can learn how to choose characteristics/aspects for particular type of business and how important is each of them according specific criteria; how to set realistic values for different characteristics/aspects of the business, how a business scenario can be changed in order to fit better to the business context (business 
reality), modeled through by the scenario template and how to assess/evaluate business scenarios. The main limitations of the model are: the degree of detail (the model is not detailed) and the limitation in regard of information volume and sources types that are accessed in real time (to assure the efficiency of the platform operation). The recommendations offered by the platform are mainly based on the limited data available during the simulation session.

As future work, we consider to enrich the architectural model, mainly by assuring a collaborative environment for simulations. In this case, the student will be able to collaborate with other students/ entrepreneurs when she/he defines a business scenario. A data mining component will be added in order to extract knowledge about the evolution of the business environment in time, analyzing the scenario templates defined in different moments of time. Also, the motivational aspect will be included by using the ARCHIMATE vers.2.1 model.

\section{Acknowledgment}

This work was supported from the European Social Fund through Sectorial Operational Programme Human Resources Development 2007-2013, project number POSDRU/159/1.5/S/134197, project title "Performance and Excellence in Postdoctoral Research in Romanian Economics Science Domain".

\section{References}

1. Arasti, Z., Falavarjani, M.K. and Imanipour, N. (2012), A Study of Teaching Methods in Entrepreneurship Education for Graduate Students, Higher Education Studies, Vol. 2, No. 1

2. Baumol, W.J. (1968), Entrepreneurship in economic theory. The American Economic Review, 58 (2):64-71

3. Bodea, C., Mogoş, R.I. and Dascălu M-I. (2012). How e-Learning Experiences Enhance the Social Presence in Community of
Practices: an Empirical Analysis, in: Christo El Morr, Pierre Maret (eds.), Virtual Community Building and the information Society: Current and Future Directions, Hershey, PA: Information Science Reference, pp. 75-120

4. Borshchev, A., and Filippov, A., (2004), From system dynamics and discrete event to practical agent based modeling: reasons, techniques, tools. In The 22nd International Conference of the System Dynamics Society, July 25-29, Oxford, England, 2004

5. Braunerhjelm, P., (2010), Entrepreneurship, Innovation and Economic Growth - past experience, current knowledge and policy implications, CESIS, Electronic Working Paper Series

6. EU (2013), Entrepreneurship Education - A Guide for Educators, Directorate-General for Enterprise and Industry European Commission

7. ECEE (2013), European Commission Entrepreneurship Education: A Guide for Educators June 2013 Bruxelles, http://ec.europa.eu/enterprise/policies/sme /promoting-

entrepreneurship/files/education/ entredumanual-fv_en.pdf

8. Garavan, T.N. and O'Cinneide, B., (1994), Entrepreneurship Education and Training Programmes: A Review and Evaluation-Part 2, Journal of European Industrial Training, $18,13-21$

9. Lackeus, M., (2013), Developing entrepreneurial competencies An actionbased approach and classification in entrepreneurial education, Division of Management of Organizational Renewal and Entrepreneurship Department of Technology Management and Economics, Chalmers University of Technology, Gothenburg, Sweden

10. OECD (2011), Entrepreneurship at a Glance. OECD Publishing, Bologna, Italy 
11. Oosterbeek. H., van Praag, M., and Ijsselstein, A., (2010), The impact of entrepreneurship education on entrepreneurship skills and motivation. European Economic Review, 54:442-452

12. Pablo-Martí, F., García-Tabuenca, A., Santos, J.L., Gallo, M.T., Mancha, T., (2013), AMOEBA : An Agent-based Model of Entrepreneurship and Business Activities, 53rd ERSA Congress, Palermo, Italy, 27-31 August 2013 Title: Special Session: S_ZI. The Spatial Dimension of Entrepreneurship

13. Paolillo R., (2014), Gender Stereotype and Female Entrepreneurship: An AgentBased Model with Protocol Beliefs-DesiresIntentions (BDI), June 16

14. Ronstad, R., (1985), The Educated Entrepreneurs: A New Era of Entrepreneurial Education is Beginning, American Journal of Small Business, 10, 7-23

15. Schelling T., (1971), "Dynamic Models of Segregation," Journal of Mathematical Sociology, 1(2), pp. 143-186

16. Schindehutte,

M.,

(2006),

Entrepreneurship Simulations, accessed September 2, 2014, http://old.ied.econ.msu.ru/cmt2/lib/c/198/ File/simulations.pdf

17. Sunny Yang, S.-J., Leeds, Y.C., (2012), Growing Artificial Entrepreneurs: Advancing Entrepreneurship Research Using AgentBased Simulation Approach, International
Journal of Entrepreneurial Behaviour and Research:

http://dx.doi.org/10.1108/1355255131131 0383, Forthcoming

18. Szirmai, A., Naudé, W., and Goedhuys, M., (2011) (eds.), Entrepreneurship, Innovation, and Economic Development

19. van der Kuip, I. and Verheul, I. (2003), Early Development of Entrepreneurial Qualities: the Role of Initial Education, SCALES-paper N200311, EIM Business and Policy Research, Netherlands

20. Vicens, L. and Grullón, S. (2011), Innovation and Entrepreneurship: A Model Based on Entrepreneur Development, InterAmerican Development Bank, http://www.iadb.org

21. Weimer, M., (2012), Five Characteristics of Learner-Centered Teaching, http://www.facultyfocus.com/articles/effect ive-teaching-strategies/five-characteristicsof-learner-centered-teaching

22. X-ABM (2014), retrieved in December, 2014, http://en.wikipedia.org/wiki/Agentbased

_model\#ABMs_in_economics_and_social_scie nces

23. X-DICT (2014), retrieved in December, 2014,

http://www.businessdictionary.com/definiti on/ entrepreneurship.html 